\title{
Analisis Kandungan TDS dan Mineral pada Air Hujan untuk Konsumsi dengan Penambahan Karbon Aktif Kulit Pisang Kepok (Musa acuminate L.)
}

Dessy Ariania, Nurhasanaha, Mega Nurhanisa ${ }^{{ }^{*}}$

aProdi Fisika, FMIPA Universitas Tanjungpura

*Email :meganurhanisa@physics.untan.ac.id

\begin{abstract}
Abstrak
Telah dilakukan penelitian tentang peningkatan kualitas air hujan menggunakan karbon aktif. Peningkatan kualitas air hujan dilakukan agar memenuhi standar baku mutu air minum menurut WHO (World Health Organization). Karbon aktif yang dipabrikasi berukuran 100 mesh berasal dari limbah kulit pisang kepok. Aktivasi karbon dilakukan dengan menggunakan kalium hidroksida (KOH). Pembuatan dilakukan melalui 3 tahapan yaitu dehidrasi, karbonisasi, dan aktivasi. Karbon aktif digunakan sebagai media penyaring air hujan agar nilai kandungan TDS (Total Dissolved Solid), Mg (magnesium), dan Ca (kalsium) dapat meningkat. Massa karbon aktif divariasikan $10 \mathrm{~g}, 20 \mathrm{~g}$, dan $30 \mathrm{~g}$. Peningkatan kualitas air hujan relatif baik pada dosis 10 gram. Nilai TDS, Mg, dan Ca berturut-turut meningkat sebesar $62,1 \mathrm{mg} / \mathrm{L}$, $10,44 \mathrm{mg} / \mathrm{L}$, dan $0,08 \mathrm{mg} / \mathrm{L}$ dibandingkan dengan air hujan sebelum penyaringan. Oleh karena itu, dapat diketahui bahwa penggunaan karbon aktif kulit pisang kepok dengan dosis yang sesuai dapat meningkatkan nilai TDS, Mg, dan Ca dalam air hujan, walaupun belum mencapai standar baku mutu air minum menurut WHO.
\end{abstract}

Kata Kunci : air hujan, air minum, karbon aktif, kulit pisang kepok

\section{Latar Belakang}

Air hujan merupakan salah satu sumber alternatif air minum. Penggunaan air minum di Kalimantan Barat yang bersumber dari air hujan mencapai 40,72\%[1]. Curah hujan rata-rata di Kalimantan Barat tergolong menengah keatas, yaitu mencapai $269,62 \mathrm{~mm}$ per tahun[2]. Jumlah curah hujan tersebut sebanding dengan tingginya kebutuhan masyarakat yang memanfaatkan air hujan sebagai air minum. Air hujan memiliki nilai TDS yang relatif rendah. Rendahnya kandungan TDS dalam air minum dapat menimbulkan gangguan sistem peredaran darah karena tubuh kekurangan mineralmineral yang diperlukan olehnya[3]. Kandungan Ca dan Mg pada air hujan hampir mendekati nol (0). Oleh karena itu, jika air tersebut dikonsumsi maka tubuh akan kekurangan Ca yang dapat menimbulkan resiko osteoporosis, karena kondisi tulang yang tidak kuat[4]. Rendahnya kandungan $\mathrm{Mg}$ pada air minum dapat menimbulkan resiko penyakit diabetes, hipertensi, penyakit jantung, dan stroke[3]. Oleh karena itu, perlu dilakukan pengujian kandungan dalam air hujan untuk mengetahui kualitas air yang akan dikonsumsi.

Kandungan mineral merupakan salah satu nutrisi yang diperlukan oleh tubuh. Mineral dapat bersumber dari buah, sayur dan air minum. Sumber mineral dari air minum dapat lebih cepat diserap oleh tubuh dibandingkan dari makanan. Hal ini dikarenakan air dapat langsung diserap oleh tubuh, sedangkan makanan harus melalui proses pencernaan terlebih dahulu[5]. Oleh karena itu, perlu dilakukan peningkatan kandungan mineral pada air minum sebagai alternatif menjaga kesehatan tubuh.

Pada umumnya karbon aktif berfungsi sebagai adsorben untuk menyerap bau, warna, dan logam pada air[6]. Selain itu karbon aktif juga dapat digunakan untuk meningkatkan kandungan TDS dan mineral pada air. Karbon aktif dari tempurung kelapa, pasir silika, dan zeolit mampu meningkatkan kandungan TDS sebesar $58 \mathrm{mg} / \mathrm{L}$, dan meningkatkan kandungan Ca hingga 55,3\% dari kandungan semula [7][8]. Oleh karena itu, karbon dapat dijadikan media untuk meningkatkan mineral pada air.

Produksi buah pisang di Kalimantan Barat tahun 2017 berjumlah mencapai 72.848 ton per tahun. Produksi buah pisang kepok (Musa acuminate L.) di Pontianak mencapai 3.330,7 ton per tahun[9]. Banyaknya buah pisang akan mempengaruhi limbah kulit pisang yang dihasilkan. Oleh karena itu, pengolahan limbah yang belum termanfaatkan perlu dilakukan untuk mengurangi dampak pencemaran lingkungan. Kulit pisang kepok mentah memiliki komposisi mineral $\mathrm{Mg} \mathrm{3,04} \mathrm{mg/100} \mathrm{g} \mathrm{dan} \mathrm{Ca}$ $11,02 \mathrm{mg} / 100 \mathrm{~g}$ [10]. Oleh sebab itu, kulit pisang kepok dapat digunakan sebagai media untuk meningkatkan kandungan mineral di air.

Penelitian ini menggunakan limbah kulit pisang kepok sebagai karbon aktif untuk meningkatkan TDS, Mg dan Ca pada air hujan. Massa karbon aktif akan divariasikan menjadi $10 \mathrm{~g}, 20 \mathrm{~g}$, dan $30 \mathrm{~g}$. Dari penelitian ini, 
diharapkan dapat mengurangi limbah kulit pisang kepok dengan cara menjadikannya sebagai karbon aktif dan memberikan informasi ilmiah mengenai potensi limbah kulit pisang kepok dalam meningkatkan kualitas air hujan untuk dikonsumsi.

\section{Metodologi}

\subsection{Alat dan Bahan}

Alat yang digunakan dalam penelitian ini adalah furnace (Carbolite), ayakan 100 mesh, wadah plastik, mangkuk keramik, timbangan digital, mortar, jeriken, gelas ukur, batang pengaduk, $\mathrm{pH}$ meter digital Senseline F470, conductivity meter Hach Sension 5 dan Atomic Absorption Spectrophotometry (AAS) Shimadzu AA-6300. Bahan yang digunakan dalam penelitian ini yaitu air hujan, kulit pisang kepok, Kalium Hidroksida (KOH) 25\%, aquades, plastik wrapping, spons, botol mineral $1500 \mathrm{ml}$, dan kertas saring.

\subsection{Pembuatan Karbon Aktif Kulit Pisang Kepok}

Kulit pisang kepok yang dijadikan bahan dasar karbon aktif sebanyak $3 \mathrm{~kg}$ dicuci bersih lalu dijemur di bawah sinar matahari. Proses dehidrasi dilakukan selama 5 hari, dengan lama penjemuran 6 jam per hari. Tujuannya untuk menghilangkan kandungan air dalam bahan baku tersebut.

Kulit pisang kepok kering dikarbonisasi menggunakan furnace pada suhu $400{ }^{\circ} \mathrm{C}$ selama 1 jam. Karbon kulit pisang kepok tersebut dihaluskan menggunakan mortar hingga berbentuk serbuk. Karbon yang telah halus ditimbang dan diayak menggunakan ayakan 100 mesh agar ukurannya seragam.

Karbon kulit pisang kepok yang telah halus diaktivasi menggunakan aktivator $\mathrm{KOH} 25 \%$. Proses aktivasi dilakukan dengan cara merendam karbon kulit pisang kepok menggunakan larutan aktivator dengan waktu kontak selama 24 jam. Pembuatan larutan aktivator menggunakan fraksi massa per volume, yaitu 25 gram $\mathrm{KOH}$ dilarutkan menggunakan aquades hingga mencapai volume $100 \mathrm{~mL}$ [11]. Rasio perbandingan antara karbon kulit pisang kepok dan aktivator adalah 2:1 atau 60 gram karbon aktif kulit pisang kepok dan 30 gram $\mathrm{KOH}$. Karbon aktif dicuci hingga mencapai pH netral dan dikeringkan menggunakan furnace pada suhu $105^{\circ} \mathrm{C}$ selama 6 jam.

\subsection{Rancangan Filter}

Filter dibuat menjadi 3 variasi, yaitu filter dengan massa karbon aktif 10 gram, 20 gram dan 30 gram. Rancangan filter air dapat dilihat pada Gambar 1.

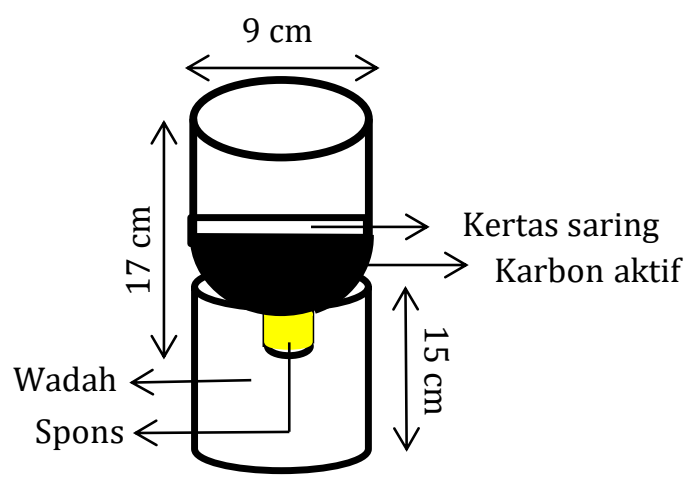

Gambar 1. Rancangan filter

Keterangan:

a. Spons digunakan untuk menahan karbon aktif agar tidak ikut turun bersama air yang disaring.

b. Wadah digunakan untuk menampung air hasil penyaringan.

c. Karbon aktif kulit pisang kepok digunakan sebagai media filter utama dalam proses filtrasi, untuk meningkatkan komposisi air yang disaring.

d. Kertas saring digunakan untuk menutup karbon aktif agar tidak naik ke permukaan ketika sampel air dituang.

\subsection{Pengujian Filter dengan Variasi Dosis Karbon Aktif}

Massa karbon aktif divariasikan menjadi 10 gram, 20 gram, dan 30 gram pada masingmasing wadah filter. Sampel air hujan sebanyak $300 \mathrm{ml}$ dituang ke dalam masing-masing wadah filter, sehingga air tersebut akan melewati karbon aktif dan mengalir ke dalam wadah penampungan. Air hasil penyaringan tersebut diuji kandungan didalamnya. Parameter yang diuji yaitu TDS, Mg, dan Ca. Pengujian dilakukan di Laboratorium Kualitas dan Kesehatan Lahan.

Hasil pengujian parameter TDS, Mg, dan $\mathrm{Ca}$ pada air hujan sesudah disaring, dibandingkan dengan hasil pengujian awal sebelum air hujan disaring. Hal tersebut dilakukan untuk melihat pengaruh variasi dosis karbon aktif terhadap setiap parameter yang diuji.

\subsection{Analisis Hasil}

Analisis dilakukan terhadap sampel awal air hujan sebelum disaring dan air hujan yang telah disaring menggunakan karbon aktif kulit pisang kepok. Kandungan TDS, Mg, dan Ca dalam air tersebut dianalisis berdasarkan standar baku mutu air minum menurut World Health Organization (WHO), untuk menentukan kelayakan air hujan agar aman dikonsumsi. Nilai persyaratan kualitas air minum menurut WHO dapat dilihat pada Tabel 1. 
Tabel 1. Persyaratan Kualitas Air Minum Menurut WHO

\begin{tabular}{lc}
\hline \multicolumn{1}{c}{ Parameter } & $\begin{array}{c}\text { Kadar minimal } \\
(\mathbf{m g} / \mathbf{L})\end{array}$ \\
\hline Fisika & $>100$ \\
\hline TDS & \\
\hline Kimia & $\geq 10$ \\
\hline Magnesium $(\mathrm{Mg})$ & $\geq 20$ \\
Kalsium $(\mathrm{Ca})$ & \\
\hline
\end{tabular}

\section{Hasil dan Pembahasan}

\subsection{Karbon Aktif Kulit Pisang Kepok}

Pembuatan karbon aktif diawali dengan proses dehidrasi. Dehidrasi adalah proses menghilangkan kandungan air yang terdapat di dalam bahan baku[12]. Pada proses dehidrasi, kulit pisang kepok mengalami penyusutan bobot sebanyak 2.409 gram. Massa kulit pisang kepok mula-mula $\left(\mathrm{m}_{1}\right)$ adalah 3000 gram, setelah dilakukan penjemuran di bawah sinar matahari massa kulit pisang kepok kering $\left(\mathrm{m}_{2}\right)$ menjadi 591 gram. Hasil penjemuran kulit pisang kepok dapat dilihat pada Gambar 2.

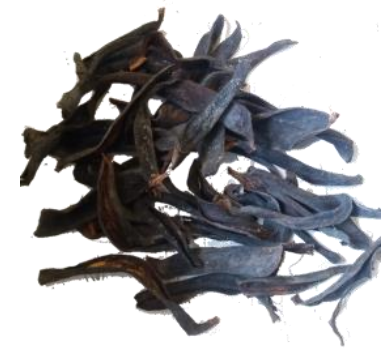

Gambar 2. Kulit pisang kepok setelah dijemur

Karbon kulit pisang kepok yang dihasilkan dari proses karbonisasi adalah 98 gram. Pada tahap karbonisasi terjadi penyusutan bobot sebanyak 493 gram. Saat proses karbonisasi berlangsung kandungan selulosa dalam kulit pisang kepok menguap dan melepaskan unsur non karbon (Hidrogen dan Oksigen). Kedua unsur non-karbon tersebut diubah dalam bentuk gas berupa gas $\mathrm{CO}$ dan $\mathrm{CO}_{2}$ [13]. Hasil karbonisasi kulit pisang kepok dapat dilihat pada Gambar 3.

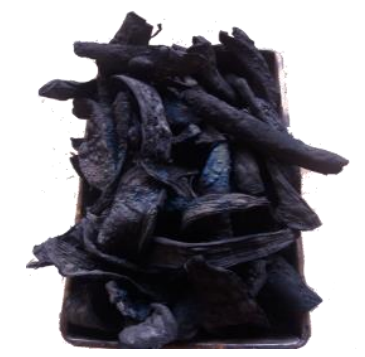

Gambar 3. Kulit pisang kepok setelah dikarbonisasi pada suhu $400^{\circ} \mathrm{C}$ selama 1 jam
Karbon kulit pisang kepok dihaluskan hingga berbentuk serbuk dan diayak menggunakan ayakan berukuran 100 mesh agar ukuran seragam.

Pada tahap aktivasi, karbon aktif kulit pisang kepok yang dihasilkan adalah 69 gram. Pada proses aktivasi terjadi penyusutan bobot sebanyak 29 gram. Hal ini disebabkan karena banyaknya karbon yang ikut terbuang saat pencucian berlangsung. Pada proses aktivasi terjadi penambahan luas permukaan karbon. Hal ini dikarenakan reaksi aktivator terhadap karbon, sehingga zat-zat pengotor pada permukaan karbon aktif hilang[16]. Hasil aktivasi karbon aktif kulit pisang kepok dapat dilihat pada Gambar 4. Karbon aktif kulit pisang kepok yang dihasilkan berwarna hitam pekat dan tidak berbau.

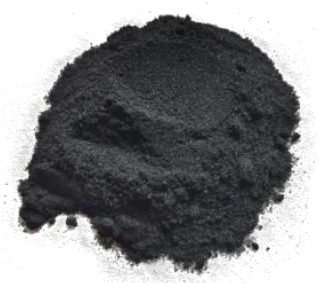

Gambar 4. Hasil aktivasi karbon aktif kulit pisang kepok berukuran 100 mesh menggunakan aktivator $\mathrm{KOH} 25 \%$

\subsection{Pengujian Air Hujan Sebelum Difilter}

Sampel air hujan yang digunakan dalam penelitian ini memiliki karakteristik warna yang bening dan jernih, seperti ditunjukkan pada Gambar 5.

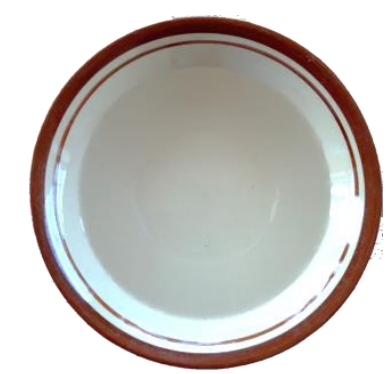

Gambar 5. Sampel air hujan $300 \mathrm{ml}$

Hasil pengujian air hujan sebelum disaring menggunakan karbon aktif kulit pisang kepok dapat dilihat pada Tabel 2 .

Pengujian sampel awal air hujan pada Tabel 2 menunjukkan bahwa air hujan belum memenuhi standar baku mutu air minum WHO. Rendahnya nilai TDS pada air hujan dikarenakan kandungan mineral dalam air tersebut relatif sedikit. Hal ini dikarenakan air yang jatuh berinteraksi dengan udara sebelum mencapai tanah. 
Tabel 2. Kandungan nilai air hujan sebelum difilter

\begin{tabular}{|c|c|c|c|}
\hline Parameter & $\begin{array}{l}\text { Nilai } \\
\text { (mg/L) }\end{array}$ & $\begin{array}{c}\text { Standar } \\
\text { WHO } \\
\text { (mg/L) }\end{array}$ & Ket \\
\hline TDS & 2,6 & $>100$ & $\begin{array}{c}\text { Belum } \\
\text { layak } \\
\text { konsumsi }\end{array}$ \\
\hline $\mathrm{Mg}$ & 0,06 & $\geq 10$ & $\begin{array}{c}\text { Belum } \\
\text { layak } \\
\text { konsumsi }\end{array}$ \\
\hline $\mathrm{Ca}$ & 0,01 & $\geq 20$ & $\begin{array}{c}\text { Belum } \\
\text { layak } \\
\text { konsumsi }\end{array}$ \\
\hline
\end{tabular}

\subsection{Pengujian Air Hujan Setelah Difilter Menggunakan Karbon Aktif Kulit Pisang Kepok}

Secara fisik, sampel air hujan setelah difilter menggunakan karbon aktif kulit pisang kepok terlihat sama. Air hujan tetap bening dan jernih, seperti ditunjukkan pada Gambar 6.

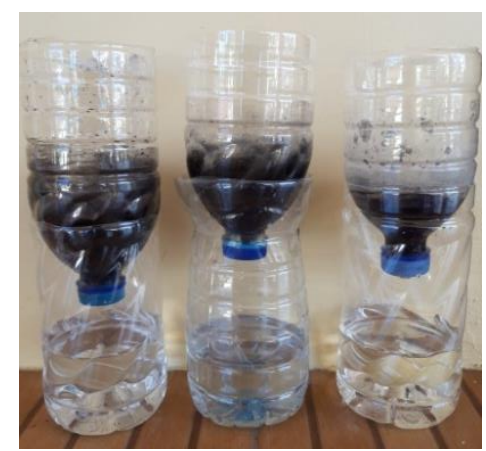

Gambar 6. Air hujan setelah disaring dengan variasi karbon aktif yang berbeda

Hasil pengujian sampel air hujan setelah dilakukan penyaringan dengan variasi massa karbon aktif $10 \mathrm{~g}, 20 \mathrm{~g}$, dan $30 \mathrm{~g}$ dapat dilihat pada beberapa parameter berikut ini.

\section{a. Magnesium (Mg)}

Magnesium merupakan salah satu mineral di air yang berperan penting bagi kesehatan tubuh. $\mathrm{Mg}$ dapat mengurangi resiko penyakit diabetes, hipertensi, penyakit jantung, stroke serta mengatur fungsi kerja saraf dan otot[3].

Grafik hasil pengujian kandungan Mg air hujan setelah dilakukan penyaringan menggunakan karbon aktif kulit pisang kepok dapat dilihat pada Gambar 7. Kandungan $\mathrm{Mg}$ untuk setiap variasi karbon aktif tidak menunjukkan pola naik atau turun. Pada variasi massa karbon aktif 10 gram terjadi peningkatan kandungan Mg paling tinggi, tetapi pada massa karbon aktif 20 gram terjadi peningkatan terendah dari kandungan semula. Hasil pengujian menunjukkan anomali nilai Mg pada massa karbon aktif 20 gram, karena kandungan Mg pada massa tersebut lebih rendah dari 30 gram. Artinya kemampuan menyerap karbon aktif pada dosis 20 gram lebih tinggi daripada dosis 30 gram. Kemampuan menyerap karbon aktif dapat dipengaruhi oleh luas permukaan karbon, ukuran partikel dan waktu kontak[15]. Oleh karena itu, anomali hasil pengujian $\mathrm{Mg}$ dapat dipengaruhi beberapa faktor tersebut sehingga kandungan Mg tidak menunjukkan pola naik atau turun.

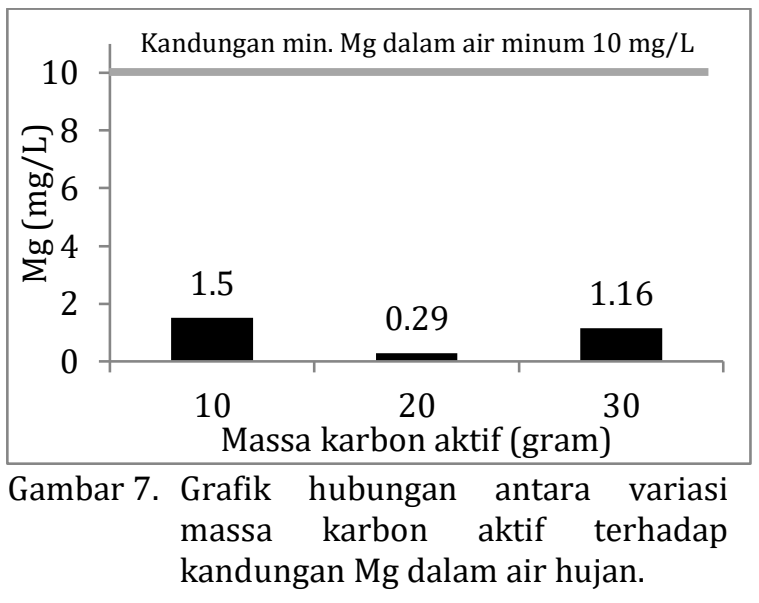

Air hujan setelah disaring menggunakan karbon aktif kulit pisang kepok mengalami peningkatan nilai Mg dari kandungan Mg mulamula. Pada air hujan, kandungan Mg mula-mula adalah $0,06 \mathrm{mg} / \mathrm{L}$. Pada variasi dosis karbon aktif 10 gram, 20 gram, dan 30 gram terjadi peningkatan nilai Mg dari kandungan mula-mula sebesar $1,44 \mathrm{mg} / \mathrm{L}, 0,23 \mathrm{mg} / \mathrm{L}$, dan $1,1 \mathrm{mg} / \mathrm{L}$. Nilai Mg meningkat setelah disaring menggunakan karbon aktif kulit pisang kepok karena pada kulit pisang kepok memiliki kandungan $\mathrm{Mg}$ sebesar 3,04 mg/100g[10]. Peningkatan mineral dalam air setelah disaring dapat dipengaruhi oleh karbon aktif yang ikut terlarut dalam air, sehingga kandungan mineral setelah penyaringan lebih tinggi dari kandungan semula[8]. Reaksi yang terjadi antara magnesium dengan air pada proses penyaringan adalah sebagai berikut:

$$
\mathrm{Mg}^{2+}+\mathrm{H}_{2} \mathrm{O} \rightarrow \mathrm{Mg}\left(\mathrm{OH}_{2}\right)
$$

Kandungan minimum $\mathrm{Mg}$ dalam air minum adalah $10 \mathrm{mg} / \mathrm{L}[16]$. Kandungan $\mathrm{Mg}$ pada air hujan setelah disaring menggunakan karbon aktif kulit pisang kepok belum layak untuk dikonsumsi karena tidak mencapai nilai standar baku mutu air minum WHO. Kandungan Mg relatif baik pada dosis karbon aktif 10 gram, yaitu sebesar $1,5 \mathrm{mg} / \mathrm{L}$.

b. Kalsium (Ca)

Kalsium merupakan zat gizi yang dibutuhkan oleh tubuh untuk pembentukan gigi 
dan tulang. Selain itu Ca dapat mempercepat proses pembekuan darah ketika luka, dan mengatur metabolisme tubuh. Kekurangan asupan Ca dapat menimbulkan resiko osteoporosis, karena kondisi tulang yang tidak kuat[6].

Grafik hasil pengujian kandungan Ca pada air hujan setelah dilakukan penyaringan menggunakan karbon aktif kulit pisang kepok dapat dilihat pada Gambar 8.

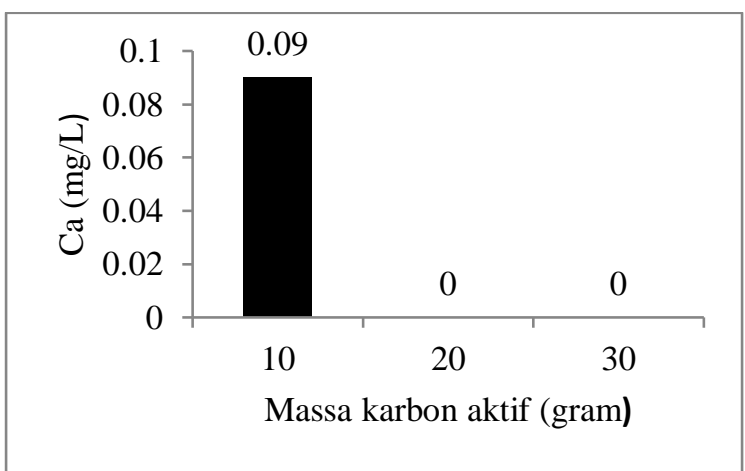

Gambar 8. Grafik hubungan antara variasi massa karbon aktif terhadap kandungan $\mathrm{Ca}$ dalam air hujan.

Kandungan Ca pada air hujan setelah disaring menggunakan karbon aktif kulit pisang kepok cenderung menurun. Semakin banyak massa karbon aktif yang digunakan, maka daya serap karbon semakin meningkat[17]. Pada variasi dosis karbon aktif 10 gram, 20 gram, dan 30 gram mengalami penurunan seiring dengan bertambahnya massa karbon aktif.

Kandungan Ca dalam air hujan setelah disaring menggunakan karbon aktif kulit pisang kepok meningkat dari kandungan Ca mula-mula pada variasi dosis 10 gram. Kandungan Ca mulamula adalah $0,01 \mathrm{mg} / \mathrm{L}$, sedangkan setelah dilakukan penyaringan menjadi 0,09 mg/L. Pada penambahan massa karbon aktif 20 gram dan 30 gram nilai kandungan Ca mencapai $0 \mathrm{mg} / \mathrm{L}$. Hal ini dapat disebabkan oleh pengaruh peningkatan daya serap karbon aktif sehingga menyerap Ca di dalam air hingga mencapai 0 . Faktor penyebab lainnya yaitu karena keterbatasan pengujian sampel tanpa ada pengukuran berulang sehingga hasil pengukuran tidak presisi. Reaksi antara kalsium dengan air pada proses penyaringan adalah sebagai berikut:

$$
\mathrm{Ca}^{2+}+\mathrm{H}_{2} \mathrm{O} \rightarrow \mathrm{Ca}\left(\mathrm{OH}_{2}\right)
$$

Kandungan minimum Ca dalam air minum adalah $20 \mathrm{mg} / \mathrm{L}[16]$. Kandungan Ca pada air hujan setelah dilakukan penyaringan menggunakan karbon aktif kulit pisang kepok belum mencapai nilai baku mutu tersebut, sehingga belum layak untuk dikonsumsi. Akan tetapi kandungan Ca relatif baik pada dosis karbon aktif 10 gram, yaitu terjadi peningkatan menjadi $0,09 \mathrm{mg} / \mathrm{L}$.

\section{c. Total Dissolved Solid (TDS)}

TDS adalah jumlah padatan terlarut dalam air, nilai TDS menunjukkan kandungan zat organik dan anorganik, mineral serta material yang terlarut di dalamnya [18]. Grafik hasil pengujian kandungan TDS air hujan setelah dilakukan penyaringan menggunakan karbon aktif kulit pisang kepok dapat dilihat pada Gambar 9.

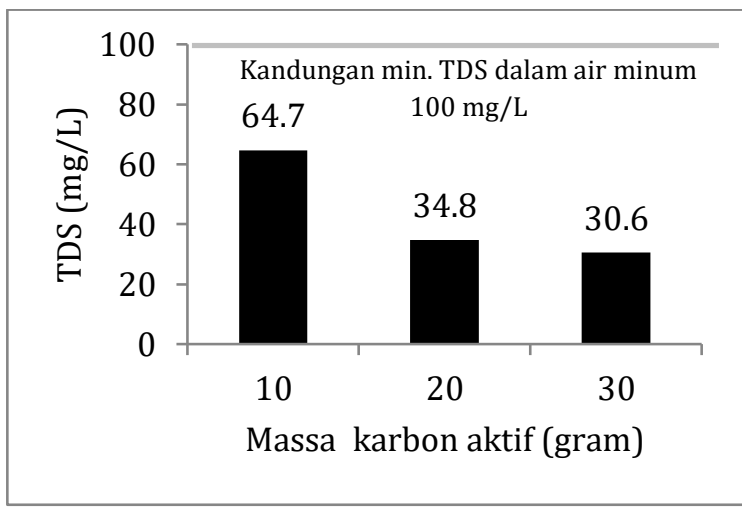

Gambar 9. Grafik hubungan antara variasi massa karbon aktif terhadap kandungan $\mathrm{pH}$ dalam air hujan.

Kandungan TDS air hujan setelah disaring menggunakan karbon aktif kulit pisang kepok mengalami penurunan. Pada variasi dosis karbon aktif kulit pisang kepok 10 gram, 20 gram, dan 30 gram kandungan TDS menurun seiring dengan penambahan massa karbon aktif. Hasil pengujian menunjukkan kandungan TDS berbanding terbalik terhadap dosis karbon aktif. Hal ini dikarenakan semakin banyak massa karbon aktif yang digunakan, maka daya serap karbon semakin meningkat[17]. Peningkatan massa karbon aktif akan mengakibatkan peningkatan daya serap karbon aktif tersebut terhadap zat yang akan diserap[19]. Oleh karena itu, nilai TDS cenderung menurun seiring bertambahnya massa karbon aktif.

Kandungan TDS air hujan setelah disaring menggunakan karbon aktif kulit pisang kepok mengalami peningkatan nilai dari air hujan mula-mula $(2,6 \mathrm{mg} / \mathrm{L})$. Pada variasi dosis karbon aktif 10 gram, 20 gram, dan 30 gram nilai TDS meningkat sebesar 62,1 mg/L, 32,2 $\mathrm{mg} / \mathrm{L}$, dan $28 \mathrm{mg} / \mathrm{L}$. Nilai TDS dipengaruhi oleh padatan yang terlarut dalam air berupa unsur, senyawa, dan koloid[20]. Peningkatan kandungan TDS setelah air hujan disaring relatif disebabkan oleh unsur Mg dan Ca yang berasal dari kandungan bahan kulit pisang kepok. Pada 
kulit pisang kepok terdapat kandungan Mg 3,04 $\mathrm{mg} / 100 \mathrm{~g}$ dan Ca 11,02 mg/100g[10]. Karbon aktif dapat meningkatkan kandungan TDS dalam air seiring dengan meningkatnya kandungan mineral dalam air tersebut[7].

Kandungan TDS minimum dalam air minum adalah $100 \mathrm{mg} / \mathrm{L}[16]$. Kandungan TDS air hujan yang dihasilkan setelah proses penyaringan menggunakan karbon aktif kulit pisang kepok belum layak untuk dikonsumsi menjadi air minum, namun kandungan TDS relatif meningkat dari kandungan TDS mula-mula. Kandungan TDS tertinggi dihasilkan dari penyaringan menggunakan karbon aktif kulit pisang kepok pada massa 10 gram, sehingga kandungan TDS relatif baik pada massa tersebut.

\section{Kesimpulan}

Berdasarkan penelitian yang telah dilakukan, dapat disimpulkan bahwa limbah kulit pisang kepok dapat dijadikan karbon aktif untuk meningkatkan kandungan mineral pada air hujan. Penambahan dosis karbon aktif kulit pisang kepok dalam penyaringan air hujan menunjukkan hasil relatif baik pada dosis 10 gram. Hasil pengujian TDS dan mineral pada air hujan setelah disaring menggunakan karbon aktif kulit pisang kepok relatif meningkat, namun belum mencapai baku mutu air minum dari WHO.

\section{Daftar Pustaka}

[1] Badan Pusat Statistik, Persentase Rumah Tangga Menurut Provinsi dan Sumber Air Minum 2000-2016, https://www.bps.go.id/statictable/2014/0 9/10/1361/persentase-rumah-tanggamenurut-provinsi-dan-sumber-air-minum2000-2016.html (Accessed 9 Agustus 2019).

[2] Badan Pusat Statistik, Jumlah Curah Hujan dan Jumlah Hari Hujan di Stasiun Pengamatan BMKG, 2000-2017, https://kalbar.bps.go.id/statictable/2015/ 04/09/115/jumlah-curah-hujan-danjumlah-hari-hujan-di-stasiun-pengamatanbmkg-2000-2017.html (Accessed 9 Agustus 2019).

[3] Coates, P., Encyclopedia of Dietary Supplements, Informa Healthcare, 2010.

[4] Mulyani, E., Konsumsi Kalsium pada Remaja di SMP Negeri 201 Jakarta Barat Tahun 2009, Universitas Indonesia, 2009.

[5] Azoulay, A., Garzon, P., dan Eisenberg, M.J., Comparison of the Mineral Content of Tap Water and Bottled Waters, Journal of
General Internal Medicine, 16, 168-175, 2001.

[6] Dewi, T.K., Nurrahman, A., dan Permana, E., Pembuatan Karbon Aktif dari Kuli Ubi Kayu (Mannihot esculenta), Jurnal Teknik Kimia, 1(16), 24-20, 2009.

[7] Salim, N., Rizal, N.S., dan Vihantara, R., Komposisi Efektif Batok Kelapa sebagai Karbon Aktif untuk Meningkatkan Kualitas Air Tanah di Kawasan Perkotaan, Media Komunikasi Teknik Sipil, 24, 87-95, 2018.

[8] Suyanta, Kholid, H.I., dan Bambang, S., Pemisahan Ion Logam Ca dan Fe dalam Air Sumur Secara Kolom Adsorpsi dengan Zeolit Alam dan Karbon Aktif, Jurnal Sains Dasar, 4(1), 87-91, 2015.

[9] Badan Pusat Statistik, Statistik Pertanian Tanaman Sayuran dan Buah-buahan Provinsi Kalimantan Barat 2017, https://kalbar.bps.go.id/publication/down load.html (Accessed 9 Agustus 2019).

[10] Okorie, D.O., Eleazu C.O., dan Nwosu P., Nutrient and Heavy Metal Composition of Plantain (Musa paradisiaca) and Banana (Musa paradisiaca) Peels, Journal of Nutrition \& Food Sciences, 5(3), 1-3, 2015.

[11] Ulfia, S.M.M., dan Astuti, Sintesis Karbon Aktif dari Kulit Durian Untuk Pemurnian Air Gambut, Jurnal Fisika Unand, 3(4), 5561, 2014

[12] Miranti, S., T., Pembuatan Karbon Aktif dari Bambu dengan Metode Aktivasi Terkontrol Menggunakan Activating Agent $\mathrm{H}_{3} \mathrm{PO}_{4}$ dan $\mathrm{KOH}$, Universitas Indonesia, 2012.

[13] Bahtiar, A., Faryuni, I.,D., dan Jumarang, M., I., Pengaruh Suhu Kalsinasi Pada Pembuatan Karbon Aktif Kulit Durian Sebagai Adsorben Logam Berat Pada Air Sungai, Prisma Fisika, 3(1), 5-8, 2015.

[14] Teng, H., dan Hsu, L.Y., High Porosity Carbon Prepared from Bituminous Coal with Potassium Hydroxide Activation, Journal of Ind Eng Chem, 2947-2953, 2000.

[15] Syauqiah, I., Amalia, M., Kartini, H.A., Analisis Waktu Kontak dan Kecepatan Pengaduk Pada Proses Adsorpsi Limbah Logam Berat dengan Arang Aktif, InfoTeknik, 12(1), 11-20, 2011.

[16] World Health Organization, Guidelines for Drinking-Water Quality, http://apps.who.int/iris/bitstream/10665 /254637/1/9789241549950-eng.pdf?ua=1 (Accessed 25 Agustus 2019)

[17] Irwandi, R., Yenti, S.R., dan Chairul, Penentan Massa dan Waktu Kontak Optimum Adsorpsi Karbon Aktif dari Ampas tebu sebagai Adsorben Logam Berat Pb, JOM FTEKNIK, 2(2), 1-9, 2015. 
[18] Mukhtasor, Pencemaran Pesisir dan Laut, PT. Pradnya Paramita, 2007.

[19] Wijayanti, H., Karbon Aktif dari Sekam Padi: Pembuatan dan Kapasitasnya untuk Adsorpsi Larutan Asam Asetat, Info-Teknik, 10(1), 61-67, 2009.

[20] Situmorang, M., Kimia Lingkungan, FMIPA Universitas Negeri Medan, 2012. 